\title{
AS SEGUNDAS RESIDÊNCIAS E O PROCESSO RECENTE DE URBANIZAÇÃO DOS MUNICÍPIOS DE ITAPEMA E BOMBINHAS - SC DECORRENTE DO USO DO TURISMO E DO LAZER
}

SECOND HOMES AND THE RECENT PROCESS OF URBAN DEVELOPMENT IN THE TOWNS OF ITAPEMA AND BOMBINHAS - SC, BASED ON TOURISM AND RECREATIONAL USE

LAS SEGUNDAS RESIDENCIAS Y EL RECIENTE PROCESO DE URBANIZACIÓN DE LOS MUNICIPIOS DE ITAPEMA Y BOMBINHAS (SC) COMO CONSECUENCIA DEL USO DEL

TURISMO Y DEL OCIO

Doris Van Meene Ruschmann

Docente e Pesquisadora do Curso/Programa de Pós-graduação em Turismo e Hotelaria, em nível de Mestrado e Doutorado - Universidade do Vale do Itajaí. d.ruschmann@univali.br.

Cálidon Costa da Conceição Doutorando em Turismo e Hotelaria pela Universidade do Vale do Itajaí - SC. calidoncosta@gmail.com Julia Mendes Vieira Graduanda em Arquitetura e Urbanismo Universidade do Vale do Itajaí - SC juliamendesv@gmail.com Marcos Arnhold Junior Doutorando em Turismo e Hotelaria pela Universidade do Vale do Itajaí - SC. Prof. dos Cursos de Turismo, Hotelaria e Gastronomia - UNIVALI marcosjunior@edu.univali.br

Data de Submissão: 12/08/2015 Data de Aprovação: 08/09/2015 
RESUMO: A presente pesquisa tem como objetivo analisar a urbanização recente decorrente do uso e do consumo do espaço para o lazer e para o turismo no sistema urbano de Itapema e Bombinhas, litoral centro-norte de Santa Catarina, verificando em que medida esse processo assume características de urbanização dispersa. O trabalho consiste em focar no processo de produção do espaço e da constituição do território urbano promovido pela dinâmica do turismo e por outras dinâmicas econômicas complementares ou concorrentes. Para isso, identificaram-se as especificidades da urbanização emergente a partir da refuncionalização de áreas litorâneas para o lazer e o turismo, caracterizando o padrão de interação espacial decorrente da dinâmica propiciada pelas atividades de lazer e turismo. A metodologia utilizada nesta pesquisa foi bibliográfica, documental e de campo. Os dados foram coletados por meio de entrevistas estruturadas aplicados junto às imobiliárias nos espaços estudados, e representados por meio de mapas, gráficos, quadros e tabelas. Os resultados indicam que tanto Itapema quanto Bombinhas, duas cidades do litoral centro-norte de Santa Catariana, apresentam um crescimento nos empreendimentos intencionados a segundas residências. É uma região cujo usuário/turista descansa, cria vínculos com o lugar ou até se dedica a um trabalho temporário - tornando-se, assim, um destino turístico de segunda residência.

Palavras-Chave: Turismo. Segunda Residência. Território Urbano. Planejamento do Turismo.

ABSTRACT: This research aims to analyze the recent urbanization resulting from the use and consumption of space for leisure and tourism in the urban system of Itapema and Bombinhas, on the central northern coast of the state of Santa Catarina, and to determine the extent to which this process assumes features of urban dispersion. The work focuses on the process of production of the space, and the constitution of the urban territory promoted by the dynamics of tourism and other complementary or competing economic dynamics. For this, the specifics of emerging urbanization were identified, based on the refunctionalization of coastal areas for leisure and tourism, characterizing the pattern of spatial interaction resulting from the dynamics provided by the leisure and tourism activities. The methodology used in this research consisted of bibliographical, documentary, and field research. Data were collected through structured interviews applied to real estate professionals in the spaces studied, and represented in the form of charts, graphs, charts and tables. The results indicate that both Itapema and Bombinhas have shown a growth in the construction of second homes. It is a region where the user/tourists can rest, create links with the place or even take temporary work - making it a second home tourism destination.

Keywords: Tourism. Second home. Urban territory. Tourism planning.

RESUMEN: El presente estudio tiene como objetivo analizar la urbanización reciente resultante del uso y del consumo del espacio para el ocio y para el turismo en el sistema urbano de Itapema y Bombinhas, costa centro norte de Santa Catarina, verificando en qué medida ese proceso asume características de urbanización dispersa. El trabajo consiste en enfocar el proceso de producción del espacio y de la constitución del territorio urbano promovido por la dinámica del turismo y por otras dinámicas económicas complementarias o concurrentes. Para ello se identificaron las especificidades de la urbanización emergente a partir de la refuncionalización de áreas costeras para el ocio y el turismo, caracterizando el modelo de interacción espacial resultante de la dinámica propiciada por estas actividades. La metodología utilizada en esta investigación fue bibliográfica, documental y de campo. Los datos fueron recolectados por medio de entrevistas estructuradas aplicadas en las inmobiliarias de los espacios estudiados, y representados por medio de mapas, gráficos, cuadros y tablas. Los resultados indican que tanto Itapema como Bombinhas, dos ciudades de la costa centro norte de Santa Catarina, presentan un crecimiento en los emprendimientos destinados a segundas residencias. Es una región cuyo usuario/turista descansa, crea vínculos con el lugar o incluso se dedica a un trabajo temporario - convirtiéndose así en un destino turístico de segunda residencia.

Palabras Clave: Turismo. Segunda Residencia. Territorio Urbano. Planeamiento del Turismo. 


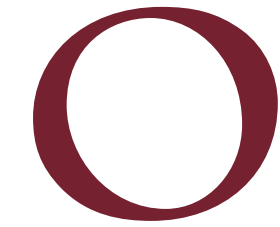
litoral centro-norte de Santa Catarina passa por um intenso crescimento no processo de desenvolvimento urbano. No entanto, a maioria dos municípios se encontra envolvida em problemas ambientais e urbanísticos. Um desses problemas seria a existência de muitos imóveis para o uso ocasional. Com a economia desses municípios ligada ao turismo e com o aumento populacional na época do verão (dezembro a março), as cidades passam por momentos em que a infraestrutura não é o suficiente para manter a cidade com um funcionamento adequado para os residentes e turistas. As cidades de Itapema e Bombinhas foram as que tiveram um maior crescimento de domicílio de uso ocasional - residência secundária, e seriam as mais afetadas por esse aumento populacional repentino na época de férias. Nesta pesquisa adotou-se o termo segunda residência para "propriedades particulares utilizadas, temporariamente, por pessoas que tem sua residência permanente em outro lugar" (TULIK, 2001).

Destarte, esta pesquisa teve como objetivo analisar a urbanização recente decorrente do uso e do consumo do espaço para o lazer e para o turismo no sistema urbano de Itapema e Bombinhas, litoral centro-norte de Santa Catarina, verificando em que medida esse processo assume características de urbanização dispersa. 0 crescimento na procura de segundas residências promoveu uma alta valorização turística na região e uma crescente existência de domicílios de uso ocasional.

A pesquisa teve como delimitação espacial o litoral centro-norte de Santa Catarina, compreendendo os municípios de Itapema e Bombinhas. A escolha destes municípios justifica-se pelo fato de se constituir importante área turística e por concentrar novos investimentos imobiliários destinados à segunda residência. Os investimentos efetuados nas últimas décadas têm provocado o aumento populacional, decorrente do aumento da procura destas localidades para a construção de residências permanentes ou da transformação das segundas residências em primeira ou residência principal, ou seja, são áreas de intensa produção imobiliária, cuja dinâmica está fortemente vinculada à sua valorização turística. 
Em relação à delimitação temporal, o foco das análises ocorreram no período que iniciaram os investimentos do PRODETUR/SUL (2000 - 2012), até os dias atuais. A medida que o programa se constituía num marco importante para o turismo nas localidades enfocadas, ao mesmo tempo coincidiam com os dados disponíveis dos últimos censos (2000-2010), cujos investimentos públicos intensificaram o processo de urbanização, primeiramente nas faixas litorâneas.

Para o alcance dos objetivos foram realizados os seguintes procedimentos metodológicos: levantamento do estado da arte pertinente ao tema em voga; atualização dos dados referentes aos investimentos do PRODETUR SUL/SC por meio da consulta à Secretaria de Estado de Turismo, Cultura e Esporte (SOL); levantamento e atualização de dados referentes aos investimentos da infraestrutura viária recente, efetuados por meio de programas governamentais; levantamento de dados sobre os domicílios de uso ocasional, domicílios de uso permanente e evolução populacional junto ao IBGE, observando os dados da última década censitária (2000-2010); e caracterização das tendências dos investimentos imobiliários mais recentes no que se refere à tipologia, à natureza, às dimensões, ao padrão, à composição, junto às empresas do setor imobiliário com entrevistas realizadas nas imobiliárias consideradas relevantes nas cidades Itapema e Bombinhas.

Para a realização da coleta de dados da pesquisa, foram selecionados 12 corretores de imobiliárias dos municípios de Itapema e Bombinhas que tivessem maior tempo de instalação e atuação nesta atividade, de modo que suas respostas fossem um aporte para contribuir com a investigação. Assim o tratamento dos dados levantados foram apresentados por meio de quadros, gráficos, tabelas, mapas, em que se buscou não somente apontar os resultados alcançados, mas, principalmente, utilizar a linguagem própria da cartografia, para compreender de maneira mais aprofundada a questão estudada de acordo com as variáveis apresentadas.

\section{NÚCLEOS TURÍSTICOS DE SANTA CATARINA}

Posterior à duplicação da rodovia federal BR-101, em 1999, foi notada uma nova fase da atividade turística no litoral de Santa Catarina, o que consequentemente trouxe novas perspectivas turísticas para a região cortada 
por pela referida rodovia. Com um melhor acesso, as cidades de Itapema e Bombinhas, por exemplo, foram tendo um crescimento devido à vinda de pessoas para passarem as férias, aumentando o movimento de veraneio (dezembro a março), que seria a época de maior movimentação turística na região. As cidades foram se preparando para suportar este novo momento econômico, o que levou à construção de novos edifícios para as residências de uso ocasional.

O litoral centro-norte de Santa Catarina, conhecido como um território turístico consolidado, é dividido pela Secretaria de Turismo Esporte e Lazer de Santa Catarina (2013) em seis núcleos atividades turísticas diversificadas, como se vê na Figura 01.

Figura 01 - Núcleos de Atividades Turísticas

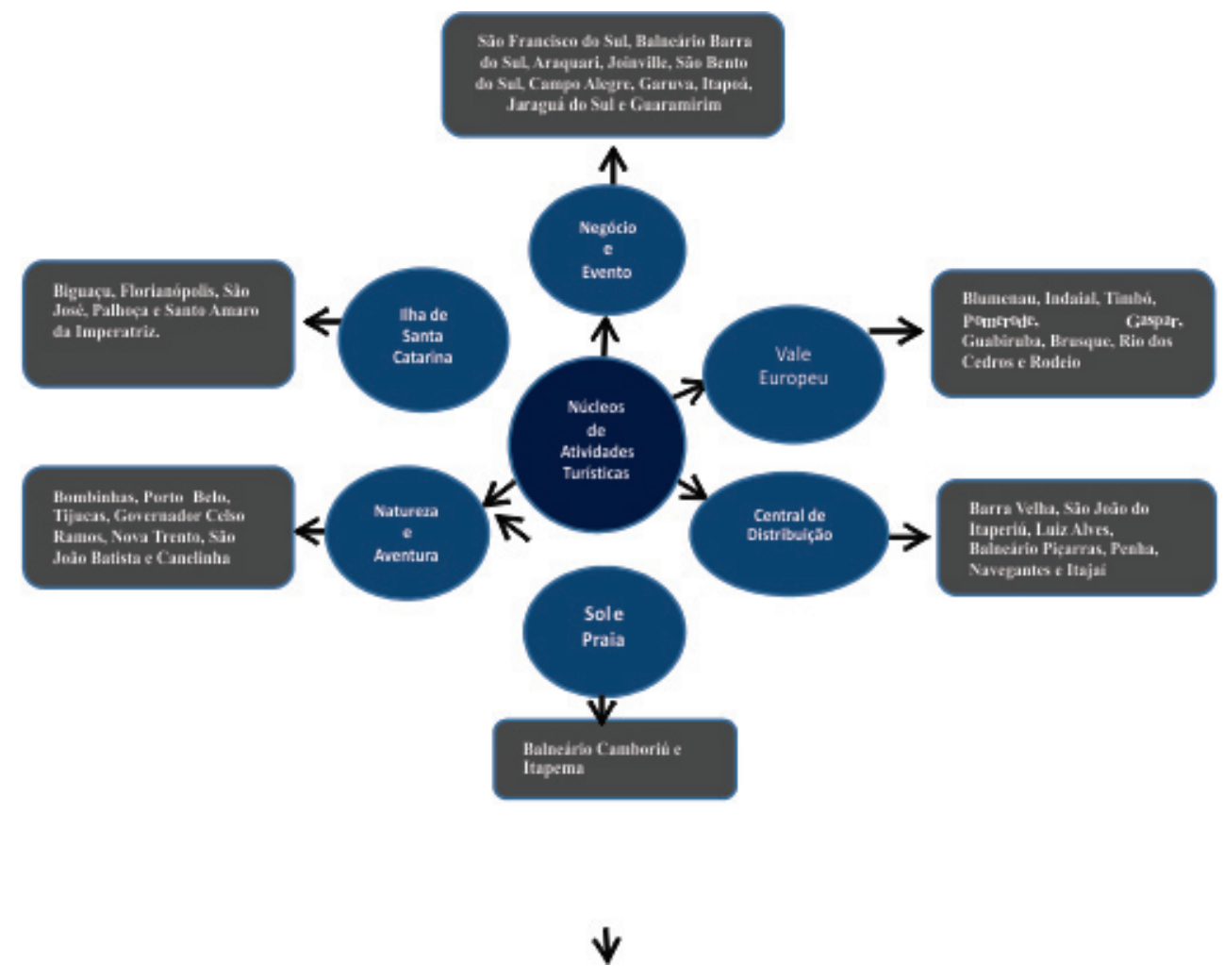

Fonte: Elaborada pelos autores, 2014.

- Negócio e Evento: envolvem os municípios São Francisco do Sul, Balneário Barra do Sul, Araquari, Joinville, São Bento do Sul, Campo Alegre, Garuva, Itapoá, Jaraguá do Sul e Guaramirim. Essas cidades formam o maior polo industrial de Santa Catarina. A região harmoniza processo econômico com desenvolvimento humano e conservação da natureza e do patrimônio histórico-cultural. 
- Vale Europeu: fazem parte os municípios de Blumenau, Indaial, Timbó, Pomerode, Gaspar, Guabiruba, Brusque, Rio dos Cedros e Rodeio. Colonizados por imigrantes europeus, principalmente alemães. Foram preservados os costumes na culinária, na arquitetura, no folclore, nas danças e nas festas religiosas.

- Centro de Distribuições: os municípios de Barra Velha, São João do Itaperiú, Luiz Alves, Balneário Piçarras, Penha, Navegantes e Itajaí fazem parte do polo turístico. Destaca-se por possuir o terceiro maior centro de captura e beneficiamento de pescado da América Latina.

- Sol e Praia: encontram-se as cidades de Balneário Camboriú e Itapema, ambas destacam-se por terem característica litorâneas misturadas com um ambiente de centro urbano movimentado.

- Natureza e Aventura: tem como municípios o de Bombinhas, Porto Belo, Tijucas, Governador Celso Ramos, Nova Trento, São João Batista e Canelinha, conhecidos pelas praias com areias brancas e água azuis e pelo verde que as emoldura. Esses núcleos apresentam informações necessárias para o planejamento e gestão de políticas públicas em relação ao setor turístico da região.

- Ilha de Santa Catarina: é uma região que alia desenvolvimento urbano com preservação de uma natureza exuberante. Possui muitas praias, áreas de preservação permanente, montanhas, dunas e duas grandes lagoas: a do Peri, o maior reservatório de água doce da ilha; e a da Conceição. Os municípios que constituem são Biguaçu, Florianópolis, São José, Palhoça e Santo Amaro da Imperatriz (SOL, 2014).

Os municípios de Itapema e Bombinhas estão inseridos nos núcleos turísticos de Sol e Praia e Natureza e Aventura e apresentam forte presença de residência secundária, que suscitou um maior foco nestes municípios para que pudesse compreender o processo de expansão das segundas residências.

Segundo informações da Prefeitura de Bombinhas (2014), Itapema foi emancipada de Porto Belo em 21 de março de 1962. Bombinhas, no mesmo caminho, foi emancipada também de Porto Belo em 30 de março de 1992. 
Ambas continuam com forte dependência dos demais municípios da região num esforço de atração de um conjunto de cidades (litoral centro-norte), buscando uma complementação de atrativos turísticos. Com o passar dos anos, desde a emancipação, a inadequação/falta de planejamento urbano em ambas as cidades se tornou um dos maiores problemas enfrentados, causando vários transtornos relativos à degradação ambiental e à ocupação desordenada. Itapema possui uma estrutura completa para pequenos e médios eventos, o que torna a cidade um complexo turístico com maior inserção nacional e internacional, e que, no caso de Bombinhas, ainda não se percebe o mesmo desenvolvimento.

As duas cidades possuem um histórico semelhante de ocupação com processo iniciado em meados do século XIX, com a vinda de imigrantes açorianos. Bombinhas, antes mesmo da época dos colonizadores, possui uma história formada por tribos indígenas, as quais preferiam viver perto do mar por sobreviverem da pesca e do plantio. Com a chegada de 6.071 pessoas na ilha dos açores, culturas e modos de vivência foram sendo fixados na região, por exemplo, as técnicas de pesca. Foi depois de 1960 que a população se mudou para as áreas planas, como se constata na Prefeitura de Bombinhas (2014).

Itapema, outrora com economia comandada por pescadores e colonos agricultores de origem açoriana, viu, desde a década de 1970, uma forte mudança para a economia voltada ao turismo; e já na década de 80 virou um polo turístico consolidado, aumentando a indústria da construção civil, situação que persiste até os dias atuais.

\section{SEGUNDA RESIDÊNCIA E ESPECULAÇÃO IMOBILIÁRIA}

Percebeu-se a necessidade de incorporar o estudo sobre a segunda residência pela magnitude dos investimentos nesta categoria imobiliária, ocasionando em uma nova configuração espacial dos litorais brasileiros. Deste modo, essa nova tipologia de domicílio interfere na dinâmica do turismo, definindo um novo tipo de turismo: o "turismo residencial".

Dada essa importância, o IBGE criou uma categoria específica para a residência secundária, denominada "domicílio de uso ocasional". A partir de 1991 este 
dado começa a ser contabilizado, bem como nos anos posteriores, nos Censos de 2000 e 2010. Assim, foi possível analisar a expansão da segunda residência no país. Especificamente, será verificado como vem se comportando essa nova estrutura no litoral catarinense, fazendo uma comparação com o litoral do Rio Grande do Norte, estudado por Maria Aparecida Pontes da Fonseca.

A definição de residência secundária é comumente aplicada às propriedades particulares utilizadas, temporariamente, por pessoas que têm sua residência permanente em outro lugar (TULIK, 2001). Assim sendo, o turismo domiciliar pode apresentar finalidades distintas: para o lazer ou o descanso, ou até trabalho, desde que seu uso seja temporário (FONSECA, 2012). Já HiernauxNicolas (2005, p.3) dedine o "turismo de segunda residência" como "Aqueles através do qual as pessoas se deslocam a um destino ou uma localidade que não é necessariamente turística, onde ocorre a posse de um imóvel através de compra, aluguel, ou empréstimo e no qual pernoitam e realizam atividades de ócio e espairecimento".

A nova dinâmica de turismo traz novos usuários, que se diferenciam do turista tradicional. Os usuários de segunda residência se diferem pela frequência que retornam à localidade, o que possibilita um vínculo territorial - afetivo ou psicológico com o lugar; e de vizinhança e sociabilidade com os usuários e moradores locais (FONSECA, 2012).

Assim, passam a existir nichos de segunda residência, onde investidores buscam fatores locacionais, que segundo Lopes Colás (2003) são: a paisagem, o clima, a acessibilidade, a presença de serviços comerciais e públicos e o valor do solo. A incidência de domicílios de uso ocasional, conforme Cruz (2007), ocorre com mais intensidade próximas aos maiores centros emissores de turistas, os quais acomodam as melhores vias de acesso, gerando viagens mais rápidas.

A partir destes aspectos, essa tipologia de edificação apresenta dupla funcionalidade para seus proprietários: local de descanso e lazer próprio e para seus familiares, bem como um investimento rentável. O segundo aspecto constitue um fator importante para a compreensão da expansão recente deste fenômeno (FONSECA, 2012). 
Pode-se dizer que a segunda residência é uma propriedade não utilizada frequentemente, que na maior parte das vezes é familiar e de lazer. Apesar de ainda estarem localizadas mais perto dos centros urbanos, hoje, com a melhoria das vias e a criação de acessos, há residências mais distantes. Seus usuários são predominantemente famílias que estão à procura de um lugar de descanso e utilizam uma parte do ano para aproveitar os fatores locacionais em que se encontra seu investimento.

Nesta pesquisa o conceito usado será ligado ao turismo de segunda residência das regiões de Itapema e Bombinhas, considerando que essa seria a tipologia de maior ocorrência nas cidades. A residência nessas cidades é usada somente durante um período do ano, dando prioridade ao uso para lazer e descanso. Depois seus proprietários voltam à cidade na qual possuem residências fixas pelo resto do ano.

A especulação imobiliária está diretamente ligada à ocupação do espaço urbano, mais especificamente como o mesmo é distribuído. A valorização de terra é equivalente a uma espécie de capital, que conforme as cidades crescem e aderem a novas e melhores infraestruturas, a valorização aumenta. Rodrigues (1997, p.17) diz que "A terra é um equivalente de capital, por que se 'valoriza' sem trabalho, sem uso" e complementa: "É um valor que se valoriza pela monopolização do acesso a um bem necessário à sobrevivência e tornado escasso e caro pela propriedade". Tudo isso interfere no aumento do preço dos imóveis de uma região.

Hoje em dia, alguns loteamentos são feitos em área de difícil acesso e com pouca infraestrutura. Assim, são vendidos lotes a baixo custo. Conforme o morador for se adaptando, ele mesmo vai fazer com que a região mude, trazendo assim mais pessoas. Consequentemente a região necessitará de abastecimento e comércios variados, o que trará movimento e a consequente valorização.

Os valores para essa mercadoria, a terra, são calculados conforme a propriedade, quem são seus compradores, o lucro dos investimentos e muitos outros fatores que atingiram um número muitas vezes elevado (CORRÊA, 1995). 


\section{URBANIZAÇÃO E RESIDÊNCIA SECUNDÁRIA}

Para a análise das residências secundárias ou de uso ocasional, como também é chamada, foi usado como base a teoria de Fonseca (2012), tendo como principal entendimento as residências secundárias a partir do turismo e do lazer.

Como principais informações, há o crescimento da construção civil voltada às segundas residências, a especulação imobiliária na região, as reformas e as melhorias na infraestrutura das cidades e, principalmente, o aumento da economia voltada somente ao turista. Tudo isso tem gerado a expansão da residência secundária. Assim desenvolve-se o turismo de segunda residência em lugares compreendidos no contexto de atividade turística, cujos usuários seriam os turistas.

Uma residência familiar é considerada secundária quando é utilizada somente parte do ano, de forma estacional, periódica ou esporádica e não constitui residência habitual de uma ou várias pessoas. Pode ser, portanto, uma casa de campo, praia ou cidade utilizada nas férias, verão, finais de semana, trabalhos temporais ou em outras ocasiões. (LÓPES COLÁS, 2003, p. 29).

Dentre as cidades do litoral centro-norte, foram escolhidas Itapema e Bombinhas, por terem um amplo crescimento de domicílios de uso ocasional entre 2000 e 2010.

A ampliação do foco de discussão sobre a urbanização para além das referências dos espaços que se encontram num processo tradicional de metropolização, com uma metrópole compacta, polarizando uma rede urbana hierarquizada, permite contribuir para a análise de espaços de urbanização cujas cidades médias são protagonistas, gerando processos muito similares aos que Indovina (2004) faz referência: a um novo processo de metropolização como uma tendência de integração dos diversos agregados urbanos e de territórios da urbanização difusa.

Nesta direção, os sistemas metropolitanos tendem a passar de uma hierarquia mais rígida para uma hierarquia mais flexível. Assim, os valores da 
cidade, que antes estavam restritos à tradicional cidade compacta, difundem-se pelo território, permitindo que a sociedade urbana se encontre fora dos limites tradicionais da cidade. Esta compreensão retrata inoperância da dicotomia rural-urbano (CORRÊA, 1995).

Portas, Domingues e Cabral (2003) consideram que o paradigma da hierarquia rígida dos sistemas urbanos, próprio dos modelos christallerianos, deixou de ser a única forma de se compreender tais sistemas, pois eles tendem a ser cada vez mais complexos, como o caso de Porto (Portugal), analisado pelos referidos pesquisadores, o que Indovina (2004) trata como a passagem de uma hierarquia hard para uma hierarquia mais soft. Desta forma, além da tradicional polarização da metrópole em relação às cidades médias e pequenas, começa a ser percebida uma relação mais horizontal dentro do sistema urbano, emergindo o que Dematteis (1998) vai reconhecer como processo inovador de competição e cooperação.

O conceito de sistema urbano complexo parece se adequar ao contexto do litoral centro e norte de Santa Catarina, abrangendo as regiões do itoral norte (Joinville), Médio Vale do Itajaí (Blumenau) e Foz do Rio Itajaí-Açu (Itajaí). A região da Foz do Rio Itajaí-Açu é composta por uma aglomeração urbana principal na área central (formada pelas cidades de Itajaí, Navegantes, Camboriú e Balneário Camboriú), de uma aglomeração secundária ao Sul (formada pelas cidades de Itapema, Porto Belo e Bombinhas) e de uma aglomeração secundária ao Norte (formada pelas cidades de Penha e Piçarras).

A dinâmica do sistema urbano que tem Itajaí como cidade mais populosa e com maior concentração de capital se assemelha ao conceito de sistema urbano complexo, pois reflete diversas escalas (da cidade, do aglomerado, e da região), tendo em vista que as determinações nestes espaços são múltiplas e os agentes quase sempre são de fora do lugar. Tais determinações são bastante nítidas em Balneário Camboriú, que se constitui no principal destino turístico do sul do Brasil na tipologia de sol e praia, além de ser o centro principal de lazer e entretenimento para uma vasta região, que congrega mais de dois milhões de pessoas. Desta forma, a expressividade de Balneário Camboriú está relacionada a duas questões complementares: destino turístico nacional-internacional e 
centro de Lazer. Quanto à primeira questão, Balneário Camboriú se constitui um destino que atrai turistas nacionais, com destaque aos do Centro-Sul do Brasil, e estrangeiros, principalmente dos países do Cone Sul. Na segunda questão, o destino atrai usuários para as atividades de lazer e entretenimento diário ou de fins de semana tanto do aglomerado urbano, quando da região norte de Santa Catarina, e ainda de locais mais distantes, como de Curitiba (PR).

Por conseguinte, a centralidade estabelecida por Balneário Camboriú se dá em diversas escalas (do aglomerado, estadual, regional e internacional), e que na medida em se sobrepõem, imprimem a sua área central, características de um lugar onde os vários grupos sociais se encontram. Os consumidores dos equipamentos turísticos e de lazer, com diversas necessidades e interesses, partilham particularmente o espaço ao longo da orla do mar.

O sistema urbano de Itajaí, por sua vez, apresenta, demograficamente, o conjunto mais dinâmico de Santa Catarina, motivado pela convivência e pela sobreposição da produção industrial e da produção do turismo. Em Itajaí, os dados demográficos demonstram que seu crescimento econômico não é acompanhado de crescimento demográfico. Assim, o fato pode ser explicado pela conurbação existente com os municípios de Navegantes, Balneário Camboriú e Camboriú, os quais vêm recebendo incremento populacional destacável. Desse modo, o crescimento urbano deste aglomerado se tornou o mais alto de todo o Estado nas últimas décadas censitárias (1991-2000 e 20002010), indicando particularmente que a dinâmica do turismo vem promovendo expressivas concentrações urbanas, não apenas criando cidades temporárias, mas também reforçando um contexto cada vez menos sazonal para a região.

Balneário Camboriú e Itapema passam por um intenso processo de verticalização em toda a orla marítima e ampliação de infraestrutura turística. Devido à pequena extensão da área plana que permite estar próximo ao mar, esse tipo de modalidade de morar disputa entre espaços tanto térreos como aéreos, originando a verticalização e o adensamento imobiliário.

A maioria das construções em andamento está na forma de edifícios, exercendo, majoritariamente, a função de segunda residência. Tratam-se de municípios localizados na porção central do litoral catarinense, que tem no setor turístico e na construção civil as atividades econômicas mais expressivas 
atualmente. Nos edifícios já construídos, habita uma parcela inexpressiva de moradores fixos, ou seja, aqueles que os ocupam em todo o decorrer do ano.

O caso de Santa Catarina, na procura por preços mais baixos do solo urbano, situações similares acontecem em Bombinhas (42,96\%) e Piçarras (40,77\%), extremo Sul e Norte do aglomerado urbano estudado (IBGE, 2000; 2010). Situação semelhante vem ocorrendo em Itajaí (39,18\%), que apesar de estar situado na porção central do aglomerado, em vista dos custos menores solo urbano, a expansão da segunda residência é fortemente percebida. Este fato parece estar ligado não apenas à saturação do mercado imobiliário no destino turístico principal, no caso catarinense Balneário Camboriú $(0,73 \%)$, como também pelo expressivo aumento do solo urbano (Gráfico 1).

Gráfico 1 - Crescimento percentual dos domicílios de uso ocasional de cada município do aglomerado urbano de Itajaí

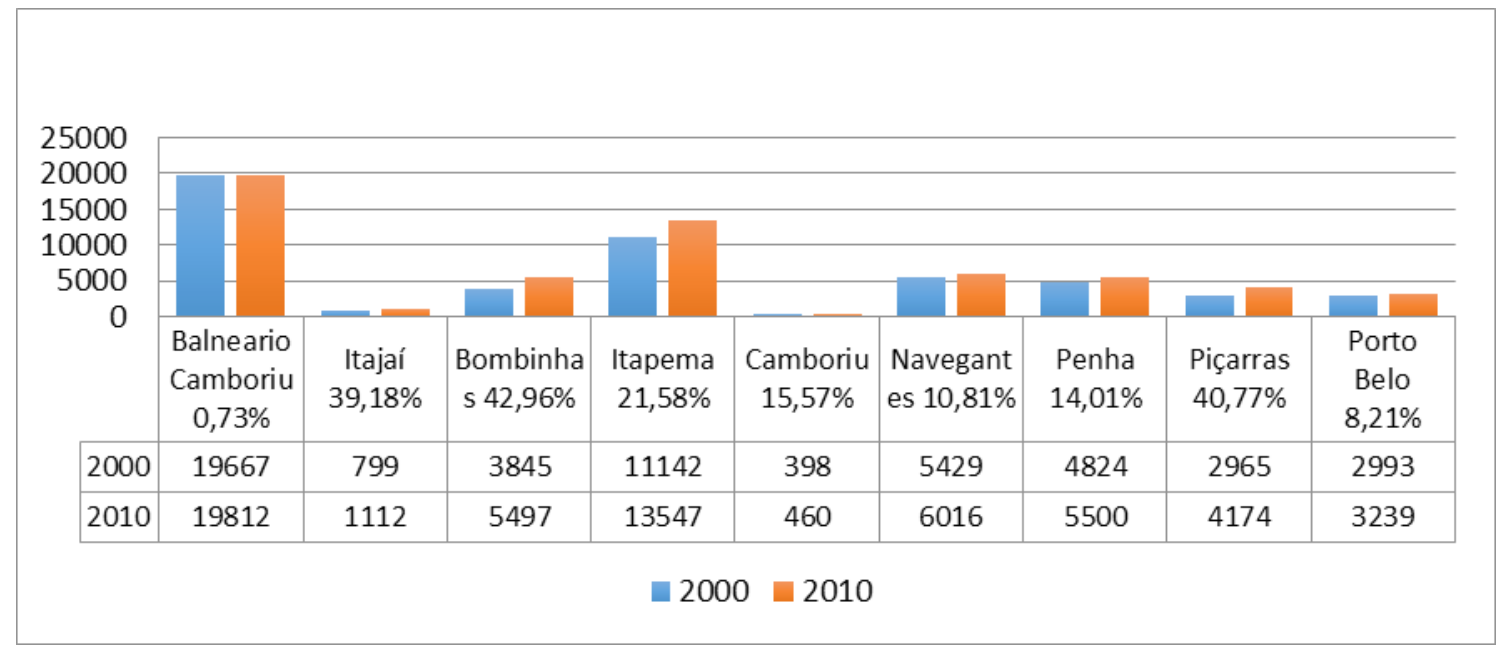

Fonte: IBGE - Censo 2000, 2010.

$\mathrm{Na}$ cidade de Bombinhas, a região com maior número de domicílios particulares permanentes de uso ocasional é a área mais próxima ao mar, principalmente das praias de Bombas e Bombinhas. Em Canto Grande, temse uma parcela pequena, mas com alta densidade de segundas residências. Aproximando-se da área mais afastada do mar, a quantidade de domicílios particulares permanentes vai equilibrando com o número dos domicílios de uso ocasional. Em solos elevados, com uma topografia mais sinuosa, encontra-se a existência de sítios. No bairro José Amândio, é o loical em que predominam os 
domicílios particulares permanentes, acredita-se que seria por ser uma região com um maior afastamento do mar.

Mapa 1 - Sinopse Censo IBGE 2010

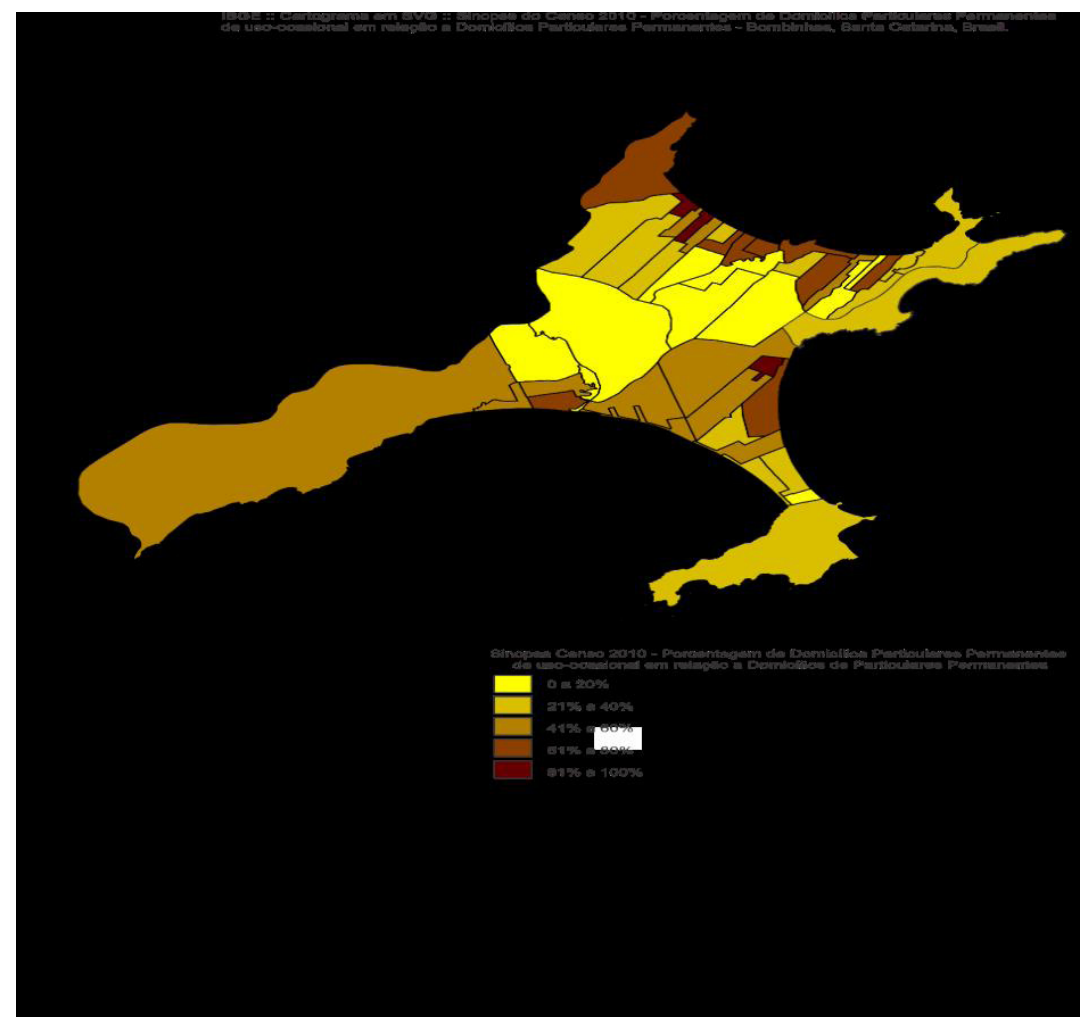

Fonte: IBGE, 2010.

$\mathrm{Na}$ cidade de Itapema, existe uma sequência de segundas residências na área mais próxima ao mar, estipulando um padrão por possuir uma faixa litorânea mais extensa. Conforme ocorre o distanciando da faixa litorânea, há uma diminuição nos números de segunda residência e novamente nota-se um crescimento somente em uma área na qual situam-se os sítios. Mais ao norte do mapa, na porção litorânea, a maior quantidade de domicílios de uso ocasional pode ser justificada pelo Hotel Plaza - um hotel que possui maior movimentação na época do verão -, onde ao lado há um condomínio de domicílios de uso ocasional. 
Mapa 2 - Sinopse Censo IBGE 2010

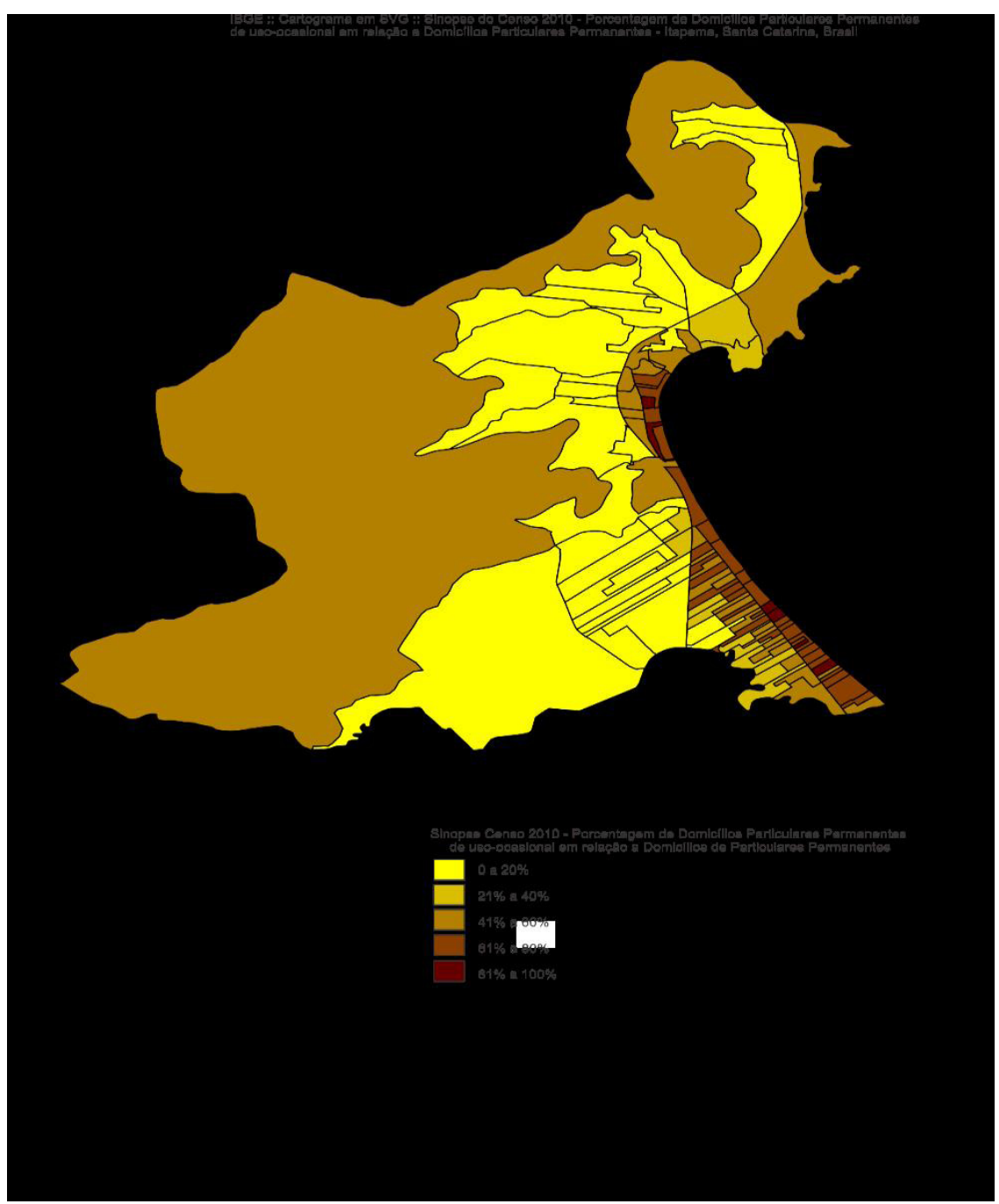

Fonte: IBGE 2010.

\section{POLÍTICAS PÚBLICAS DE TURISMO}

O crescimento de segundas residências nas regiões de Itapema e Bombinhas é altamente influenciado pelas políticas públicas municipais, estaduais e nacionais, pois é caracterizada por ter a possibilidade de influenciar o comportamento humano (VAN WERKUM; ARTS; LEEUVIS, 2000) e, além dessa influência, a sua formulação é um processo que deve ser interativo e contínuo (ZHANG; PINE; LAM, 2005). Sendo assim, durante a pesquisa de dados, notou-se essencial o uso de fontes como o Programa de Desenvolvimento Turístico do Sul do Brasil (PRODETUR SUL) na parte do turismo no âmbito econômico das regiões, Santa Catarina Turismo (SANTUR) e o Instituto de Pesquisas Sociais UNIVALI, 
no intuito de analisar os turistas, como o seu meio de hospedagem, o motivo da viagem e o Perfil da Área Turística (PAT) para obter informações sobre como estão as cidades para receber os turistas e, por fim, o Programa de Aceleração do Crescimento (PAC2) para informações sobre o desenvolvimento de obras de infraestrutura social, urbana, logística e energética de SC.

PRODETUR SUL

Foram registradas ações do PRODETUR SUL na infraestrutura de acesso, provisão de serviços públicos e controle de impactos ambientais, como o sistema de saneamento de Bombinhas e Porto Belo, a construção de rodovias turísticas de Bombinhas/Porto Belo e Itapema/Porto Belo, o sistema de esgotamento sanitário (Bombinhas e Itapema) e os terminais marítimos de passageiros em Itapema. Outras ações também foram realizadas, como a de amostra representativa por componente e unidade de federação (plano diretor municipal de Bombinhas e a implantação do sistema integrado de captação, o abastecimento e o tratamento de água e esgoto - Porto Belo e Bombinhas), os aspectos socioambientais de áreas prioritárias de desenvolvimento turístico, que se mostraram incertas as condições ambientais dos corpos d'água, sendo a praia de Bombinhas, Porto Belo e Itapema a maior parte do tempo impróprias para banho, tendo áreas com degradação e destruição, assim como manguezais, dunas e outros bens do patrimônio natural.

O Quadro 01 apresentará os principais projetos de investimento do estado de Santa Catarina para a melhoria da infraestrutura das regiões e seus impactos ambientais, conforme o documento de relatório de avaliação e gestão ambiental e social programática de 2004 - PRODETUR SUL. 
Quadro 01 - Projetos de Investimentos em Bombinhas e Itapema - Prodetur 2004

\begin{tabular}{|c|c|c|c|}
\hline Projeto & Impactos Significativos & $\begin{array}{l}\text { Medidas de } \\
\text { Controle }\end{array}$ & $\begin{array}{c}\text { Avaliação e } \\
\text { Acompanhamento }\end{array}$ \\
\hline $\begin{array}{c}\text { Sistema de } \\
\text { abastecimento de } \\
\text { água de Bombinhas } \\
\text { e Porto Belo } \\
\text { (implantação de } \\
\text { redes de distribuição, } \\
\text { adutoras e ETA). }\end{array}$ & $\begin{array}{l}\text { Impactos positivos: melhoria } \\
\text { do fornecimento de água } \\
\text { potável e atendimento à } \\
\text { população flutuante, melhoria } \\
\text { das condições sanitárias de } \\
\text { habitações e instalações de } \\
\text { serviço. } \\
\text { Impactos negativos: construção } \\
\text { - perda de vegetação natural, } \\
\text { erosão e assoreamento, } \\
\text { transtornos do trafego urbano, } \\
\text { ruído e poeira. }\end{array}$ & $\begin{array}{c}\text { - Critérios de } \\
\text { projeto contidos } \\
\text { no ROP } \\
\text { - RAP e PBA } \\
\text { - Licença Prévia } \\
\text { no 050/04 } \\
\text { - Licenças de } \\
\text { instalação e } \\
\text { operação }\end{array}$ & $\begin{array}{c}\text { - Relatórios de auditoria } \\
\text { ambiental } \\
\text { - Plano de Controle } \\
\text { Ambiental (PCA) } \\
\text { - Relatórios de supervisão } \\
\text { de obras }\end{array}$ \\
\hline $\begin{array}{l}\text { Melhoria do sistema } \\
\text { de esgotamento } \\
\text { sanitário de } \\
\text { Bombinhas } \\
\text { (ampliação de rede } \\
\text { coletora de esgotos } \\
\text { e interceptores, } \\
\text { construção de } \\
\text { elevatórias, recalque } \\
\text { e ETE em área rural, } \\
\text { emissário submarino). }\end{array}$ & $\begin{array}{l}\text { Impactos positivos: melhoria das } \\
\text { condições sanitárias na cidade, } \\
\text { da qualidade de água da bacia e } \\
\text { balneabilidade de praias, melhor } \\
\text { atendimento à população } \\
\text { flutuante. } \\
\text { Impactos negativos: construção } \\
\text { - desmatamento, transtornos de } \\
\text { tráfego, incômodos por ruído e } \\
\text { poeira, alteração de morfologia } \\
\text { de praias, operação- riscos de } \\
\text { contaminação de corpos d'água, } \\
\text { odores. }\end{array}$ & $\begin{array}{l}\text { - Critérios de } \\
\text { projeto contidos } \\
\text { no ROP } \\
\text { - Estudo } \\
\text { de Impacto } \\
\text { Ambiental } \\
\text { - LP no 052/04 } \\
\text { (parcial) } \\
\text { - Audiência } \\
\text { Pública } \\
\text { - LP do emissário } \\
\text { - PBA } \\
\text { - Outras licenças } \\
\text { e autorizações }\end{array}$ & $\begin{array}{c}\text { - Relatórios de auditoria } \\
\text { ambiental } \\
\text { - PBA/PCA } \\
\text { - Relatórios de supervisão } \\
\text { de obras }\end{array}$ \\
\hline $\begin{array}{c}\text { Sistema de } \\
\text { esgotamento } \\
\text { sanitário de Itapema } \\
\text { (implantação de rede } \\
\text { coletora, interceptores, } \\
\text { elevatórias, linhas de } \\
\text { recalque e ETE) }\end{array}$ & $\begin{array}{c}\text { Impactos positivos: melhoria } \\
\text { de condições sanitárias na } \\
\text { cidade, qualidade da água na } \\
\text { bacia e balneabilidade das } \\
\text { praias, melhor atendimento à } \\
\text { população flutuante. } \\
\text { Impactos negativos: construção } \\
\text { - desmatamento, transtornos de } \\
\text { tráfego, incômodos por ruído } \\
\text { e poeira; operação - risco de } \\
\text { contaminação de corpos d'água, } \\
\text { odores. }\end{array}$ & $\begin{array}{c}\text { - Critérios de } \\
\text { projeto contidos } \\
\text { no ROP } \\
\text { - Estudo } \\
\text { de impacto } \\
\text { ambiental } \\
\text { - Audiência } \\
\text { pública } \\
\text { - Licenças } \\
\text { ambientais }\end{array}$ & $\begin{array}{c}\text { - Relatórios de auditoria } \\
\text { ambiental } \\
\text { - PBA/PCA } \\
\text { - Relatórios de supervisão } \\
\text { de obras }\end{array}$ \\
\hline
\end{tabular}

Fonte: Programa de desenvolvimento do turismo no sul do Brasil - PRODETUR SUL. Relatório de avaliação e gestão ambiental e social programática - Outubro de 2004.

Nas tabelas de 01 a 05, foram indicadas as informações levantadas pelo PAC2, que promove a execução de grandes obras de infraestrutura social, urbana, logística e energética do país. As tabelas foram feitas a partir no $7^{\circ}$ balanço de 2013, sendo: 
- Tabela 1 apresenta os empreendimentos exclusivos;

- Tabela 2, os projetos de prevenção em áreas de risco (drenagem) em Itapema;

- Tabela 3, urbanização de assentamentos precários;

- Tabela 4, unidade básica de saúde (UBS) em Bombinhas;

- Tabela 5 - saneamento (Funasa) em Bombinhas;

Tabela 01 - Empreendimentos Exclusivos

\begin{tabular}{c|c|c|c|c|c}
\hline Tipo & Subtipo & Empreendimento & $\begin{array}{c}\text { Investimento } \\
\text { 2011 a 2014 } \\
\text { (R\$ milhões) }\end{array}$ & $\begin{array}{c}\text { Investimento } \\
\text { após 2014 (R\$ } \\
\text { milhões) }\end{array}$ & Estágio \\
\hline Rodovias & $\begin{array}{c}\text { Construção } \\
- \text { Rodovias }\end{array}$ & $\begin{array}{c}\text { BR-101/SC - Via Expressa Porto } \\
\text { de Itajaí - Acesso ao Porto de } \\
\text { Itajaí }\end{array}$ & 86,58 & - & Em obras \\
\hline Rodovias & Duplicação & $\begin{array}{c}\text { BR-470 - Duplicação } \\
\text { Navegantes - Blumenau }\end{array}$ & $* * * *$ & Em \\
\hline Rodoviação \\
de obra
\end{tabular}

Fonte: PAC, $7^{\circ}$ balanço 2013.

Tabela 02 - Prevenção em áreas de risco (drenagem)

\begin{tabular}{c|c|c|c|c|c}
\hline $\begin{array}{c}\text { Município } \\
\text { beneficiado }\end{array}$ & Proponente & Empreendimento & $\begin{array}{c}\text { Data da } \\
\text { seleção }\end{array}$ & $\begin{array}{c}\text { Investimento } \\
\text { total (R\$ } \\
\text { milhares) }\end{array}$ & Estágio \\
\hline Itapema & Município & $\begin{array}{c}\text { Drenagem - Implantação de } \\
\text { sistema de drenagem urbana } \\
\text { em diversos bairros }\end{array}$ & Jun/09 & $41.613,97$ & $\begin{array}{c}\text { Em } \\
\text { obras }\end{array}$ \\
\hline
\end{tabular}

Fonte: PAC, $7^{\circ}$ balanço 2013.

Tabela 03 - Urbanização de Assentamentos Precários

\begin{tabular}{c|c|c|c|c|c}
\hline $\begin{array}{c}\text { Município } \\
\text { beneficiado }\end{array}$ & Proponente & Empreendimento & $\begin{array}{c}\text { Data da } \\
\text { seleção }\end{array}$ & $\begin{array}{c}\text { Investimento } \\
\text { total (R\$ } \\
\text { milhares) }\end{array}$ & Estágio \\
\hline Itapema & Município & $\begin{array}{c}\text { Elaboração de estudos e } \\
\text { projetos para urbanização / } \\
\text { Praiamar / Morretes / Ilhota }\end{array}$ & Dez/10 & $* * * *$ & $\begin{array}{c}\text { Em } \\
\text { licitação } \\
\text { de projeto }\end{array}$ \\
\hline
\end{tabular}


DoI: 10.14210/rtva.v17n3.p712-736

\begin{tabular}{c|c|c|c|c|c}
\hline Itapema & Município & $\begin{array}{c}\text { Elaboração de plano local de } \\
\text { habitação }\end{array}$ & Set/07 & 69,24 & Concluído \\
\hline Itapema & Município & $\begin{array}{c}\text { Provisão habitacional - Jardim } \\
\text { Praia Mar }\end{array}$ & Jan/08 & 796,55 & Concluído \\
\hline Bombinhas & Município & $\begin{array}{c}\text { Elaboração do plano local de } \\
\text { habitação }\end{array}$ & Set/07 & 30,92 & Concluído \\
\hline Bombinhas & Município & Água em áreas urbanas & Nov/07 & 308,99 & Em obras \\
\hline
\end{tabular}

Fonte: PAC, $7^{\circ}$ balanço 2013.

Tabela 04 - UBS - Unidade Básica de Saúde

\begin{tabular}{c|c|c|c|c|c}
\hline $\begin{array}{c}\text { Município } \\
\text { beneficiado }\end{array}$ & Proponente & Empreendimento & $\begin{array}{c}\text { Data da } \\
\text { seleção }\end{array}$ & $\begin{array}{c}\text { Investimento total } \\
\text { (R\$ milhares) }\end{array}$ & Estágio \\
\hline Bombinhas & Município & Ampliação - UBS & Jun/12 & $* * * *$ & $\begin{array}{c}\text { Ação } \\
\text { preparatória }\end{array}$ \\
\hline
\end{tabular}

Fonte: PAC, $7^{\circ}$ balanço 2013.

Tabela 5 - Saneamento (FUNASA)

\begin{tabular}{c|c|c|c|c|c}
\hline $\begin{array}{c}\text { Município } \\
\text { beneficiado }\end{array}$ & Proponente & Tipo & $\begin{array}{c}\text { Data da } \\
\text { seleção }\end{array}$ & $\begin{array}{c}\text { Investimento total } \\
\text { (R\$ milhares) }\end{array}$ & Estágio \\
\hline Bombinhas & Funasa & $\begin{array}{c}\text { Elaboração } \\
\text { de projetos }\end{array}$ & Ago/11 & $* * * *$ & $\begin{array}{c}\text { Em } \\
\text { contratação }\end{array}$ \\
\hline
\end{tabular}

Fonte: PAC, $7^{\circ}$ balanço 2013.

\section{SEGUNDA RESIDÊNCIA E CRESCIMENTO URBANO}

A importância da residência secundária para o litoral centro-norte catarinense e especialmente para Bombinhas e Itapema é reconhecida por diversos dados disponibilizados por levantamentos de várias naturezas. Uma pesquisa feita pelo Instituto de Pesquisas Sociais da UNIVALI sobre a demanda turística nos municípios que integram o Consórcio Intermunicipal de Turismo Costa Verde e Mar - CITMAR (Piçarras, Penhas, Navegantes, Itajaí, Camboriú, Balneário Camboriú, Itapema, Porto Belo e Bombinhas) de caráter quanti-qualitativo, executada do dia 04 de Janeiro a 11 de Março de 2011, indica que o meio de hospedagem mais utilizado pelos turistas é o aluguel de casa, apartamento ou residências, seguido pela casa própria, hotel, casa de amigos e parentes e, por fim, a pousada. 
Considerando que as casas e os apartamentos de aluguel ou a residência própria dos turistas indicam, na sua grande maioria, ocupação de habitação de uso ocasional - segunda residência -, percebe-se que o turismo na região está fortemente baseado neste tipo de ocupação sazonal.

Na pesquisa apresentada na reportagem da revista Exame sobre o mercado Imobiliário Brasileiro, assinada por Giuliana Napolitano e Ana Luiza Leal (2014), percebeu-se um ajuste nos preços dos imóveis pela renda e pelo nível de emprego de cada cidade. Segundo a reportagem, o mercado nacional está saindo do estado de euforia. Recentemente existe maior disponibilidade de crédito, o que levou a um grupo de pessoas a um crescente potencial de compra. Itapema vem citada entre as 75 cidades com maior expressão na área, dando destaque à área central do bairro de Meia Praia, local em que se notaram os maiores preços de imóveis nesta região, sendo que a média está em $R \$ 4.731,00$ o metro quadrado. Destaque ainda os bairros Centro e Morretes, com valores um pouco mais baixos.

Na pesquisa com os corretores de imóveis, buscou-se realizar entrevistas com corretores com maior tempo de mercado imobiliário. No caso de Itapema, com um mercado mais consolidado, os corretores estão há mais de uma década no mercado. Em Bombinhas, a tempo foi reduzido, pela existência de um mercado em consolidação.

Quadro 02 - Entrevista com Corretores de Imóveis dos Municípios de Itapema e Bombinhas

\begin{tabular}{|c|c|c|c|}
\hline Município & Entrevistado & Função no estabelecimento & $\begin{array}{c}\text { Tempo de atuação no } \\
\text { mercado }\end{array}$ \\
\hline Bombinhas & E1 & Corretor e administrador & 6 anos \\
\hline Bombinhas & E2 & Corretor e administrador & 6 anos \\
\hline Bombinhas & E3 & Corretora e Secretária administrativa & 3 anos \\
\hline Bombinhas & E4 & Corretor & 2 anos \\
\hline Bombinhas & E5 & Corretora & 12 anos \\
\hline Bombinhas & E6 & Corretor & 4 anos \\
\hline Bombinhas & E7 & Corretora e administradora & 27 anos \\
\hline Itapema & E8 & Corretor e administrador & 16 anos \\
\hline Itapema & E9 & Corretor & 20 anos \\
\hline Itapema & E10 & Diretor & 23 anos \\
\hline Itapema & E11 & Corretor & \\
\hline
\end{tabular}

Fonte: Elaborado pelos autores, 2014. 
Nos dados relacionados aos estabelecimentos, a maioria dos deles possui mais de dez anos de instalação, apresentando um quadro de empresas bem estabelecidas no mercado. Todas atuam com vendas e locação, e algumas diversificam seus serviços entre imóveis, seguros e turismo.

Quadro 03 - Estabelecimentos Entrevistados

\begin{tabular}{|c|c|c|c|c|}
\hline Município & $\begin{array}{l}\text { Natureza do } \\
\text { estabelecimento }\end{array}$ & $\begin{array}{l}\text { Ano de Abertura } \\
\text { do Estabelecimento }\end{array}$ & $\begin{array}{c}\text { Número de pessoas } \\
\text { que atuam no } \\
\text { estabelecimento }\end{array}$ & Serviços realizados pela empresa \\
\hline Bombinhas & Matriz & 2005 & 8 pessoas & Venda, locação e incorporação. \\
\hline Bombinhas & Matriz & 1989 & 4 pessoas & Venda e aluguel. \\
\hline Bombinhas & Matriz & 2011 & 5 pessoas & Venda, aluguel e permuta. \\
\hline Bombinhas & Matriz & 1994 & 5 pessoas & Venda, aluguel e permuta. \\
\hline Bombinhas & Matriz & 1889 & 10 pessoas & $\begin{array}{l}\text { Venda, aluguel, incorporação e } \\
\text { permuta. }\end{array}$ \\
\hline Bombinhas & Matriz & 2003 & 4 pessoas & Venda, aluguel e permuta. \\
\hline Bombinhas & Matriz & 2013 & 5 pessoas & Venda, aluguel, permuta. \\
\hline Itapema & Matriz & 1994 & 6 pessoas & $\begin{array}{l}\text { Venda, aluguel, compra e } \\
\text { intermediações. }\end{array}$ \\
\hline Itapema & Matriz & 1999 & 5-6 pessoas & Venda, aluguel e compra \\
\hline Itapema & Matriz & 1996 & 5 pessoas & $\begin{array}{l}\text { Venda, aluguel, turismo, seguros } \\
\text { e empreendimentos imobiliários. }\end{array}$ \\
\hline Itapema & Matriz & 1978 & $10-12$ pessoas & Venda, aluguel e compra. \\
\hline
\end{tabular}

Fonte: Elaborado pelos autores, 2014.

De acordo com os corretores, em Bombinhas, na área de vendas, os compradores são provenientes dos estados da região Sul do Brasil: Rio Grande do Sul, Paraná e Santa Catarina, e no caso de aluguel, além dos estados já citados, estão incluídos São Paulo, Mato Grosso do Sul e Goiás. Quanto aos locais de maior demanda e procura por novos empreendimentos, destacamse os bairros Mariscal, 4 Ilhas e Bombas. Maior ênfase em Mariscal, que vem percebendo uma mudança num comércio ativo na baixa temporada. $A$ preocupação dos corretores quanto ao crescimento é de que a cidade recebe um repentino aumento da população, piorando os problemas com infraestrutura, e conforme reforçado pelos corretores, potencializado pela inexistência de um planejamento que acompanhe o desenvolvimento local. 
Figura 3 - Divisão dos Bairros do Município de Bombinhas

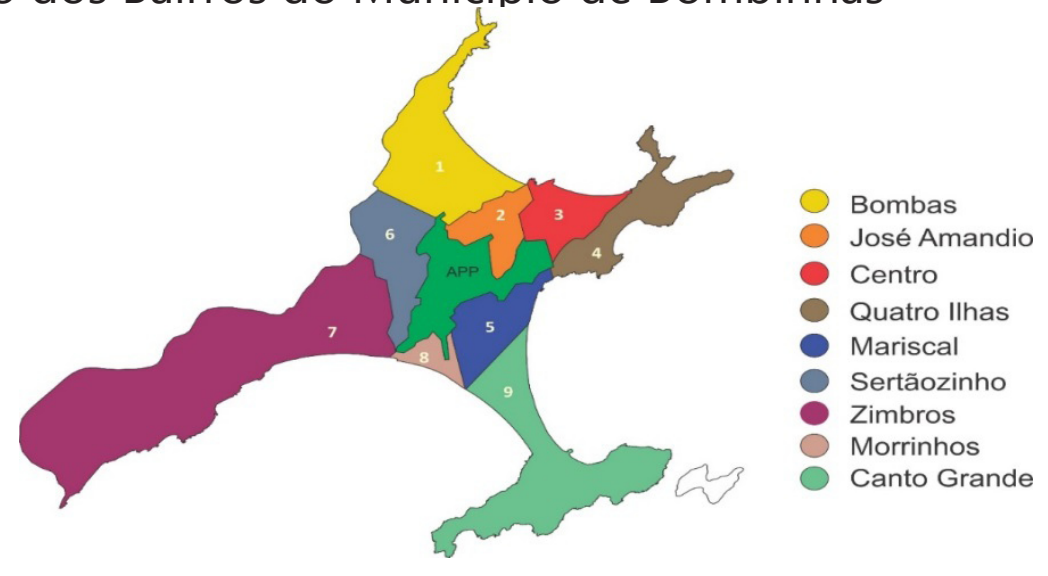

Fonte: Elaborada pelos autores, 2014.

$\mathrm{Na}$ cidade de Itapema, as áreas tradicionais dos investidores (Bairros Meia Praia e Centro) não foram alteradas, reforçando, de acordo com os corretores, o aumento dos investidores de outros países como novos compradores de imóveis. Segundo os corretores, a área que mais cresce é a de frente ao mar, sendo que $50 \%$ dos compradores investem para seu próprio uso para o lazer e outros negociam para depois vender por um valor maior. Outro destaque é o Bairro Morretes, que vem apresentando um crescimento contínuo para residências permanentes. Conforme os corretores, muitos moradores querem optar por uma área menos movimentada e com um preço mais acessível. 0 forte crescimento da construção civil na cidade não vem acompanhado de maior qualificação da mão de obra e gera um supervalorização dos terrenos. Os corretores destacam ainda que não há melhoria na infraestrutura, pois o poder público não acompanha o desenvolvimento. 
Figura 04 - Divisão dos Bairros de Itapema.
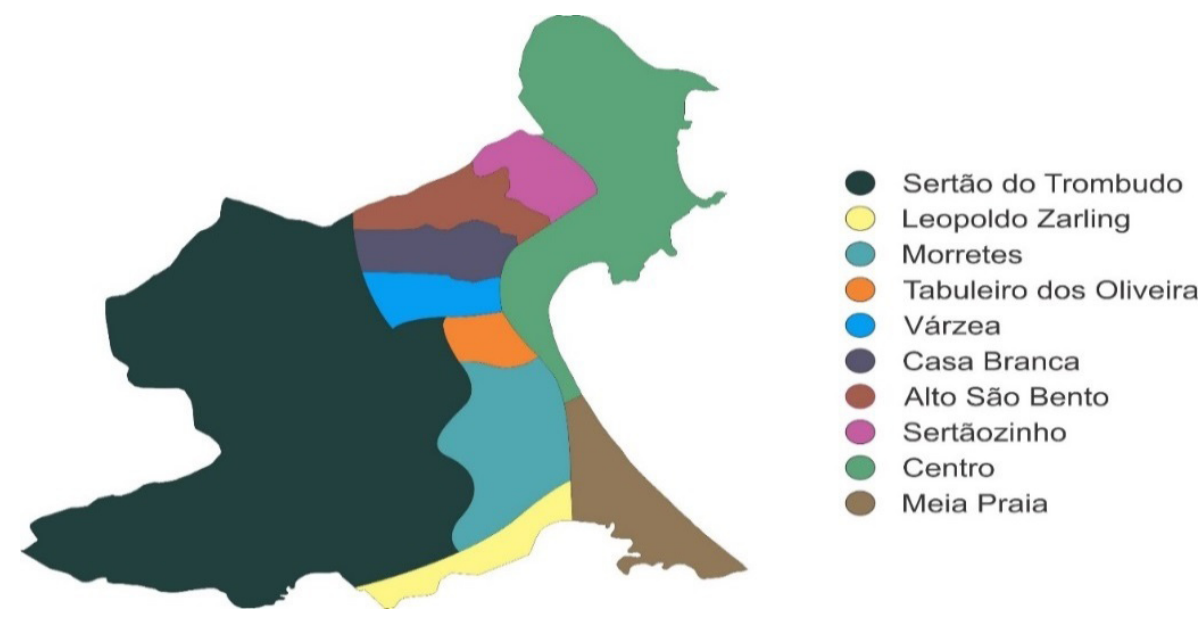

Fonte: Elaborada pelos autores (2014).

\section{CONSIDERAÇÕES FINAIS}

A partir do alto crescimento e do desenvolvimento do turismo na região do litoral centro-norte de Santa Catarina, foram escolhidas as cidades de Itapema e Bombinhas com o intuito de analisá-las conforme a economia e o crescimento de segundas residências. Entende-se que as cidades ao mesmo tempo em que apresentam um crescimento acelerado, estão enfrentando problemas na sua infraestrutura e na supervalorização de seus imóveis.

Em âmbito geral, os municípios supracitados possuem áreas de grande crescimento econômico e turístico principalmente as mais próximas do mar e, tanto em Itapema como Bombinhas, foi percebido um crescimento considerável nas áreas mais afastadas do mar, pois se acredita que serão cada vez mais construídos imóveis para residentes, que conforme o tempo serão "empurrados" pelos investidores, que tornarão cada vez mais seletiva a moradia nas faixas litorâneas, e terão como opção a moradia fixa mais afastada com um preço mais acessível.

Os investidores deste tipo de região estão à procura de lazer e descanso e têm como principal foco os investimentos para as segundas residências ao ponto de mudarem a funcionalidade da região para uma nova dinâmica com a intenção de atender, nos comércios e nos serviços, a demanda de consumo de um usuário de segunda residência. Todas as infraestruturas, desde a viária até a 
sanitária, estão vinculadas ao crescimento da população nestes dois municípios na época do verão, pois é neste período que a cidade possui maior ocupação e, consequentemente, requer melhor condições de infraestrutura.

Desta forma, Itapema e Bombinhas são as duas cidades do litoral centronorte de Santa Catarina que mais pode ser percebido o crescimento nos empreendimentos intencionados a segundas residências. São nessas cidades que o impacto do crescimento repentino em uma época do ano torna-se mais visível para os moradores, transformando o seu modo de convívio e a forma de utilização da cidade. Entretanto, mesmo com essa demanda latente, é uma região cujo usuário/turista pode descansar, criar vínculos com o lugar ou até mesmo vir a trabalhar, se for algo temporário - tornando-se, assim, um destino turístico de segunda residência.

\section{REFERÊNCIAS}

CARLOS, A.F.A. A (re)produção do espaço urbano. São Paulo: Editora da Universidade de São Paulo, 1994.

CORRÂ, Roberto L. Espaço Urbano. 3. ed. São Paulo: Ática, 1995.

CRUZ, RITA DE CASSIA ARIZA. Indrotução a Geografia do Turismo: de lugares a pseudolugares. São Paulo: Roca, 2007.

DEMATTEIS, G. Suburbaniación Y Periurbanización. Ciudades Anglosajonas Y Ciudades Latinas. In: Monclús, F.J. (Ed.). La ciudad dispersa. Suburbanización y nuevas periferias. Barcelona, CCCB, 1998. p. 35-35.

FONSECA, Maria Aparecida Pontes (Org.). Segunda residência, lazer e turismo. Natal: EDUFRN, 2012.

FRANÇA JUNIOR, Romualdo Theophanes de. A mobilidade turística no processo de planejamento da logística de transportes de Santa Catarina. 2014. (Tese de doutorado em Administração e Turismo) - Universidade do Vale do Itajaí, Biguaçu, 2014.

IBGE - Instituto Brasileiro de Geografia e Estatística. Disponível em: < http://www.ibge.gov. br/home/estatistica/populacao/censo2010/default resultados universo.shtm >. Acesso em: maio de 2014.

HIERNAUX-NICOLAS, D. La promoción inmobiliaria y el turismo residencial: el caso mexicano. 
In: Scripta Nova. Revista Electrónica de Geografia y Ciencias Sociales, vol. IX, n 194(05), ago/ 2005.

INDOVINA, F. La metropolizació del territory. FONT ARELLANO, A. (Ed.). L’explosió de la ciutat: morfologies, mirades i mocions. Barcelona: COAC, 2004. p. 12-23.

LOPES COLÁS, Julián. La residencia secundaria en España: estúdio territorial de uso y tenencia. 2003. 440 p. (Tese de Doutorado em Geografia) - Facultat de Filosofia i Lletres. Universitat Autônoma de Barcelona, 2003.

PORTAS, N.; DOMINGUES, A.; CABRAL, J. Políticas Urbanas: tendências, estratégias e oportunidades. Lisboa: CEFA/FCG, 2003.

PREFEITURA de Bombinhas. Disponível em: http:/turismo.bombinhas.sc.gov.br/a-cidade. Acesso em: 10 de ago. de 2014.

RODRIGUES, A. B. Turismo e Desenvolvimento Local. São Paulo: Hucitec, 1997.

SOL - Secretaria de Turismo Esporte e Lazer. Disponível em: http://www.sol.sc.gov.br/index. php?option=com content\&view=article\&id=19\&Itemid=27. Acesso em: maio de 2014.

TULIK, Olga. Casas de temporada. São Paulo: Roca, 2001.

VAN WOERKUN, C; AARTS, N; LEEUVIS, C. Communication strategies, tourism and the natural environment. In: H. BRIASSOULIS \& J. VAN DER, Straaten (Eds.) Tourism and the environment: Regional, economic, cultural, and policy issue. Dordrecht: Kluwer Academic. p. 240-253, 2000.

ZHANG, H.Q; PINE, R; LAM, T. Tourism and hotel development in China: From political to economic success. Howarth: Haworth Hospitality Press, 2005. 